\title{
Application of Liquid Desiccant Cooling Technology in Built Environment: A Review
}

\author{
D.B. Jani* \\ Department of Mechanical Engineering, GEC, Dahod, Gujarat Technological University, GTU, India \\ *Corresponding Author: D.B. Jani, Department of Mechanical Engineering, GEC, Dahod, Gujarat \\ Technological University, GTU, India
}

\begin{abstract}
Liquid-desiccant assisted dehumidification and cooling system has been proved to be an effective method to extract the moisture of air with relatively less energy consumption, especially compared with conventional vapor compression system. To date, the conventional dehumidification mode with desiccant solution has been improved or replaced by newly emerged energy-saving systems with better performance. This paper gives a detailed account of the general features of the various components used in desiccant dehumidification and cooling techniques; meanwhile, the effect of various operating parameters on system performance also highlighted. Moreover, a summary of the experimental and analytical studies to evaluate the system performance has been made. Some new hybrid systems that greatly expand the desiccant dehumidification technique in industrial and residential applications, as well as effectively promoting the single system's performance, are also reviewed through literature. Through a literature review, the feasibility of the desiccant cooling is proven by its comparison with conventional vapor compression system in terms of energy and cost savings are underscored. Finally, future study and application for liquiddesiccant dehumidification techniques are concluded.
\end{abstract}

Keywords: Cooling, dehumidification, liquid desiccants, regeneration, renewable energy.

\section{INTRODUCTION}

The role of the desiccant used in the dehumidifier is to remove water vapor from the conditioned air due to vapor pressure difference between the hot desiccant and the supply conditioned air. The desiccant can be categorized mainly into the two categories as solid adsorption and liquid absorbent desiccant materials. Several other types of solid materials are available in nature that can hold water vapor to the great extent to its weight, e.g., silica, polymers, zeolites, alumina and mixtures. Other commonly used liquid desiccant materials are calcium chloride, lithium chloride, lithium bromide, triethylene glycol and an equal mixture between calcium chloride and lithium chloride. These liquid desiccants have many thermo-physical properties, but their requirements cannot be fully described by any single desiccant. These requirements include low vapor pressure, low crystallization point, high density, low viscosity, low reactivation temperature, and economy [1]. The moist air is dehumidified by being brought into contact with strong liquid or solid desiccant, after this to provide sensible cooling to dehumidification process, traditional vapor compression, and vapor absorption, direct or indirect evaporative cooler units used. When the solution is weakened by absorption of moisture, it provided for the regeneration process that can loses its moisture content due to external thermal source. This called as reactivating the saturated desiccant material [2]. Thermal energy, at a temperature as low as $46-72{ }^{\circ} \mathrm{C}$ required for reactivating of the liquid desiccant can efficiently obtained using a particular type of air or water solar collector or other primary heat renewable source [3]. The typical cycle of the desiccant is made up by three processes as shown in Figure 1and Figure 2 depicts the fundamental deviation among traditionally used air conditioner and novel desiccant assisted dehumidification and cooling process [4]. The traditionally used vapor-compression cycle is now the foundation of the world air conditioning industry and will remain so for many years in conjunction with other hybrid cooling systems. The following problems are being addressed through a number of approaches including: (1) More efficient designs for household and commercial air conditioners, (2) More efficient buildings that require minimum or zero cooling, (3) The conversion 
of power generation from fossil fuels to sustainable and renewable energy resources like as freely available solar energy, (4) The development of air conditioners that provide more efficient method of drying the moisture laden air, or latent cooling, more efficient ways, and (5) A wider implementation of energy storage technologies for different commercial and residential applications. Solutions do exist using only vapor-compression technology, but these solutions will increase the cost for producing thermal comfort by use of various air conditioning technologies. So, the desiccant assisted dehumidification and cooling system as a promising option to the traditionally used vaporcompression air conditioner may be better able to control the indoor thermal comfort while meeting the new economic, environmental, and performance requirements.

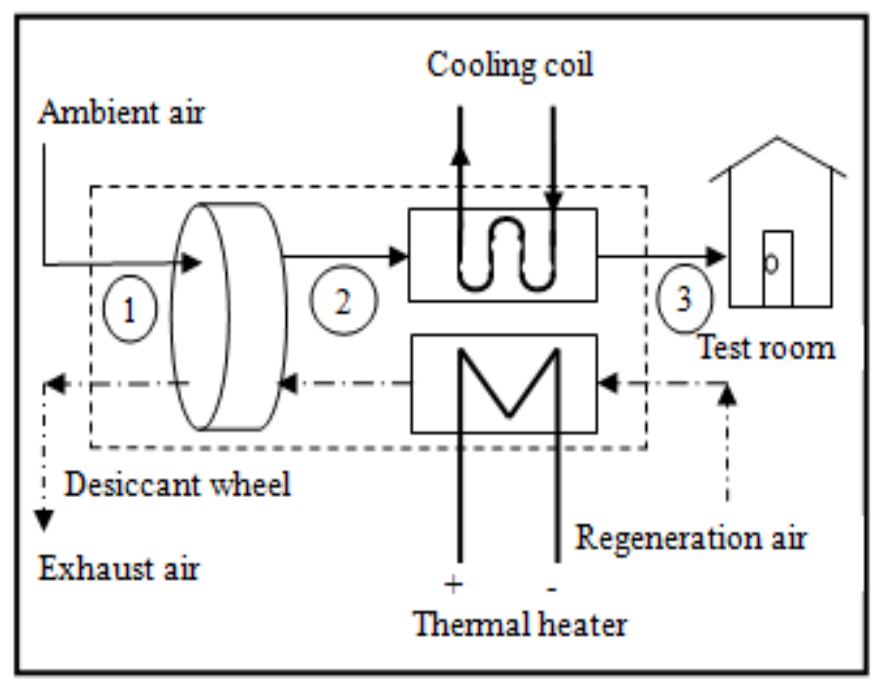

Figure1. Schematic Layout of Desiccant Integrated Dehumidification and Cooling Technique.

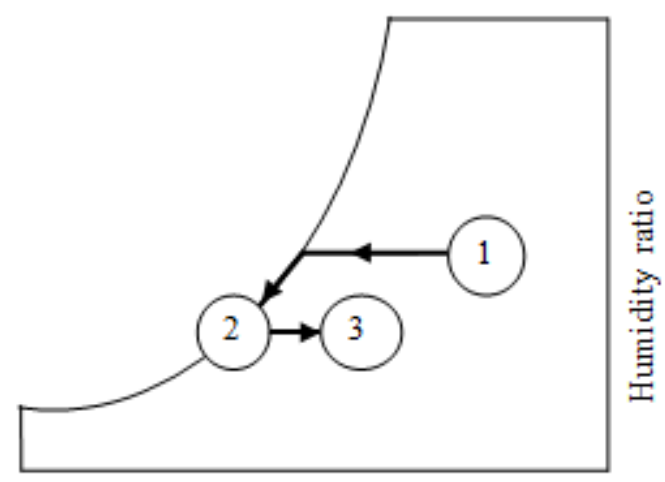

Dry bulb temperature $\left({ }^{\circ} \mathrm{C}\right)$

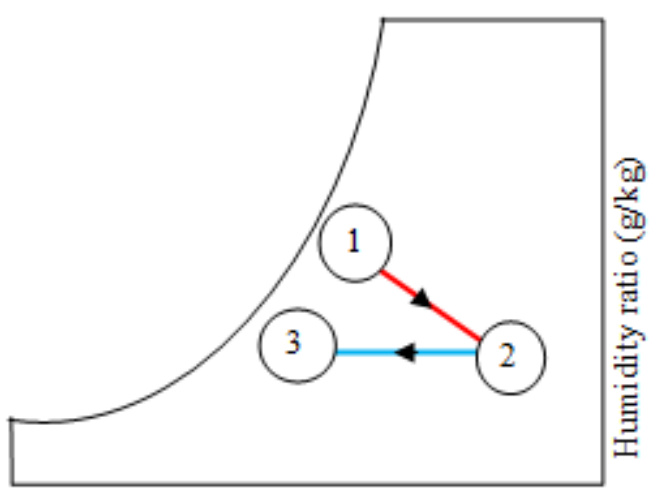

Dry bulb temperature $\left({ }^{\circ} \mathrm{C}\right)$

(a)

(b)

Figure2. Presentation (A) Conventional Cooling and (B) Desiccant Cooling on Psychometric Chart.

\section{Working PRINCIPLe OF THE LIQUID DESICCANT ASSISTED DEHUMIDIFICATION AND COOLING SYSTEM}

The liquid desiccant cooling system consists of six major components namely an air dehumidifier, regenerator, two heat exchangers, and heater, cooler. The dehumidifier or absorber consists of a packed tower and operated in an adiabatic mode. While the regenerator is a device very similar to the dehumidifier, and so are the flow system and associated components. The regeneration heat required for desiccant reactivation is supplied by regenerator. The packing materials can be categorized as random packing materials and structured packing materials, the former are materials without regular geometric forms and placed randomly in the packing tower. While the opposite structured packing materials which have fixed geometric form. Pall ring, rosette ring, ladder ring etc. are among the widely used random packing materials in gas-liquid contacting industrial equipments, such as cooling 
towers. The schematic layout of liquid-desiccant system is shown in Figure 3. The conditioner (or absorber) is the component that cools and dries the process air. As shown in this figure, the conditioner is a bed of structured contact media, similar to the corrugated fill that might be used in a cooling tower. Liquid desiccant is first cooled in a heat exchanger and then sprayed onto the contact media. The desiccant flow rate must be sufficiently high to ensure complete wetting of the media, meaning it should be about 4-6 gpm per square foot of face area. The process air is then cooled and dried as it comes in contact with the desiccant-wetted surfaces of the contact media. The absorption heat is released as the desiccant absorbs water from the air, but the high flow rate of the desiccant limits its temperature rise to a few degrees. The regenerator removes the water vapor absorbed by the desiccant during conditioning the room process air. The desiccant is reactivated by first heating it to raise its equilibrium vapor pressure. The hot desiccant, typically between $50-80^{\circ} \mathrm{C}$ temperature, is sprayed over a bed of random fill. Flooding rates are again sufficiently high to ensure complete wetting of the media. The hot desiccant desorbs water to the air that flows through the bed. This moisture laden air is typically exhausted to ambient. Both the regenerator and conditioner require droplet filters (also referred to as mist eliminators) to ensure that the desiccant is not entrained in either the supply air to the building or the exhaust from the regenerator. Droplet formation is fundamental to both the spray distributor and the highly flooded beds of contact media used in industrial equipment. Droplet filters can suppress desiccant carryover to parts per billion of airflow, but these filters do increase air-side pressure drops and require maintenance. An interchange heat exchanger (IHX) can be used to preheat the weak desiccant that flows to the regenerator using the hot, concentrated desiccant that leaves the regenerator. The IHX reduces both the thermal energy use of the regenerator and the cooling requirements of the conditioner. The corrosion effects on the operating components of the system should also be taken into account, the normal anti-corrosion methods adding additives to the liquid desiccant or choosing parts made of synthetic plastic for the system, which can simultaneously lower cost compared with metal parts.

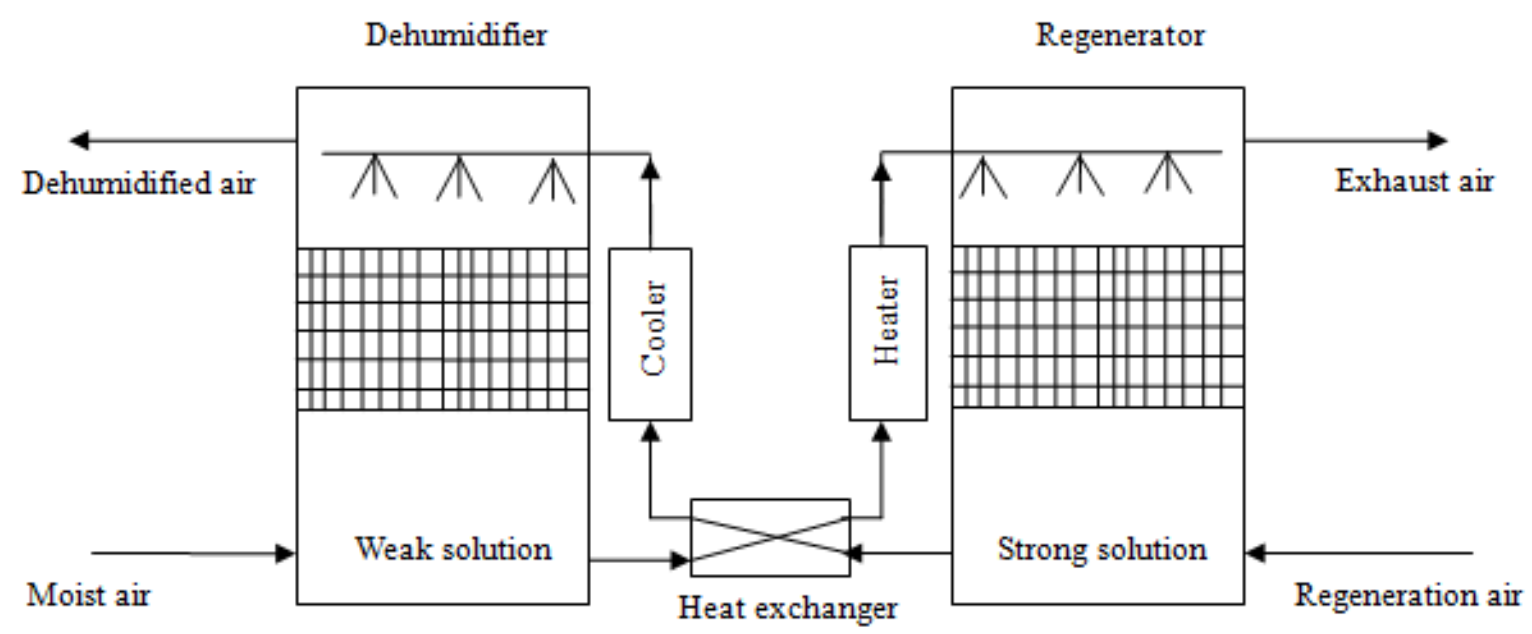

Figure3. Schematic Layout of Desiccant Assisted Dehumidification and Cooling System.

\subsection{Literature Survey on Liquid Desiccant Assisted Dehumidification and Cooling Technique}

Desiccants absorb moisture because of the difference in vapor pressure between the air and the surface of the desiccant solution. Dehumidification process is starts when the vapor pressure of the surface of the desiccant is less than that of air and continues until the desiccant reaches equilibrium with air [5]. Many investigators have conducted studies earlier on liquid desiccant dehumidification systems. Scalabrin and Scaltriti [6] performed many experiments over internally cooled dehumidifier and heated regenerator to simulate an open process of summer air conditioning. Experimental study was also investigated by $[7,8]$ to describe the mass transfer performance of a crow-flow dehumidifier and regenerator in terms of enthalpy efficiency and moisture efficiency and moisture removal rate and regenerator effectiveness, respectively. The obtained results show that the impact of air and desiccant inlet parameters on the dehumidifier and regenerator performance. Jain et al. [8] conducted experimental study on a liquid desiccant system had a falling film tubular absorber and a falling film plate regenerator. Mohammad et al. [9] proposed an artificial neural network (ANN) model for predicting the performance of a liquid desiccant dehumidifier in terms of the water condensation rate 
and dehumidifier effectiveness. MATLAB code was designed to study feed forward back propagation. The results show that the maximum percentage difference between the ANN and experimental value for water condensation rate and dehumidifier effectiveness were $8.23 \%$ and 9.75\%, respectively. Youtong and Hongxing [10] suggested an innovative configuration of an open cycle liquid desiccant system. The system uses the counter flow dehumidifier type and solar collector to regenerate the dilute solution. Two loops in the system: Liquid desiccant dehumidification loop and air dehumidification loop, also the sys-tem had two solution tanks connect to the liquid desiccant loop, the first for strong solution and the other for weak solution. Kumar [11] proposed new cycles to improve the COP and carried out experiments to study the impact of various factors on the performance of regenerator and dehumidifier. Peng and Zhang [12] simulated the heat and mass transfer processes in a solar liquid desiccant regenerator system. The results of simulation show that the increment of solution outlet concentration, regeneration efficiency, and storage capacity increase $72 \%, 46.5 \%$, and $47 \%$, respectively as effective solution proportion falls from $100 \%$ to $61 \%$. Xiong et al. [13] investigated that the COP of the system increased from 0.26 to 0.74 when used a novel twostage liquid desiccant dehumidification. Some produced chilled water [14-18] to cool the process air, so the reheat of the process air may be needed for the precise control of room air conditions. Jones [19] designed and tested low-flow liquid desiccant air handling system; a natural gas boiler uses to supply the heat and a cooling tower for heat rejection. COP of the system varied between 0.57 and 4.46. Martinez [20] suggested innovative idea to reduce the corrosion problem with use of organic absorbents instead of tri-ethylene glycol (TEG). In Taiwan [21-23] carried out a parametric study on a $9 \mathrm{~m}$ long solar $\mathrm{C} / \mathrm{R}$ and investigated that the double-glazed forced convection well suitable in humid climates. These systems have several advantages over solid desiccants, including lower pressure drop of air across the desiccant material, suitability for dust removal by filtration, ease of manipulation and greater mobility. Kumar et al. [24] simulated, analyzed and modified the performance of standalone liquid desiccant system [25]. The main components of the system were absorber and regenerator type falling film; liquid desiccant falls under gravity in the form of a thin film on the side surface of the tubes from the top of absorber/regenerator. Two ways to modify the cycle, the first, by adding one absorber in parallel with the first absorber to reduce the load on it, the COP increase from 0.26 to 0.42 and the second modify is by adding a third absorber, the COP increase to 0.56 . Li et al. [26] proposed a new regeneration method to regenerate the solution in the liquid desiccant system. The regeneration system is named photovoltaic-electro dialysis (PV-ED); a membrane is employed to regenerate the liquid desiccant in an electro dialysis, while the solar photovoltaic generator is adopted to supply electric power for this process. The new regeneration method achieves good stability with the immunity against the adverse impact from the outside high humidity; its performance is much higher than that of the thermal regeneration manner while putting aside the low efficiency of the photovoltaic system. Audah et al. [27] studied the feasibility of using a solar-powered liquid desiccant system, which used calcium chloride as liquid desiccant, parabolic solar concentrators as a heat source for regenerating the liquid desiccant the liquid desiccant model predicted the amount of condensate obtained from the humid air leaving the regenerator bed when directed through a coil submerged in cold sea water. The optimal regeneration temperature increases with decreased heat sink temperature with values of $50.2^{\circ} \mathrm{C}$ and $52.4^{\circ} \mathrm{C}$ corresponding to sink temperatures of $19.4^{\circ} \mathrm{Cand} 16.5^{\circ} \mathrm{C}$. Jain et al. [28] used a liquid desiccant system had a double channeled exchanger for air to liquid desiccant heat and mass transfer; this way provides a large area of heat and mass transfer between the air and solution. The performance of the system was presented in terms of moisture removal rates and efficiency of dehumidifier/regenerator. Most of the physical parameters are measured against a suitable reference point directly. As reported in [29], the parallel flow channel provides better dehumidification and cooling processes of the air than counter flow configuration for a wide range of pertinent parameters. A liquid desiccant sys-tem using $\mathrm{Li}-\mathrm{Br}$ for the process of absorption and dehumidification simulated by Ahmed et al. [30] with a hybrid open-cycle vapor absorption. Grossman [31] developed an open-cycle absorption chiller and desiccant system for use with low temperature heat sources such as a flat plate collector. The system consists of numbers major components, an indirect contact evaporative cooler, an air dehumidifier, two air to air heat exchanger and solution to solution heat exchanger. Artificial neural network proposed by Gandhidasan and Mohandes [32] to simulate the relationship between the inlet and outlet parameters of the dehumidifier in the liquid desiccant system. The results show that the dehumidification process can be alternatively modeled using artificial neural network with a reasonable degree of accuracy. Babakhani et al. [33] developed an analytical solution of the coupled heat and mass transfer process in a cross- 
flow liquid-desiccant dehumidifier/regenerator. The results of the analytical solution show that air flow rate, air inlet humidity, desiccant inlet temperature, and desiccant inlet concentration have more influence on the moisture removal rate in the cross-flow dehumidifier, while desiccant flow rate, desiccant inlet temperature, desiccant inlet concentration, and air inlet humidity have more effect on the moisture removal rate in the regenerator. Lowernstein [34] studied mixtures of lithium chloride and calcium chloride as a lower-cost alternative to lithium chloride. The cost for calcium chloride is approximately one-twentieth that of the lithium salt. Mohamad et al. [35] reviewed the use of the alternatives for high latent air conditioners based on a conventional vapor-compression cycle. These advanced air conditioners typically add a heat and/or mass exchanger in the airstream to lower the sensible heat ratio (SHR) of the cooling process. These modified vapor-compression air conditioners have lower energy efficiency ratios (EER) than conventional units because of the additional air-side pressure drops across the added heat/mass exchangers. Table 1 shows below the summary of important work carried out previously in the field of desiccant cooling.

Table1. Summary sheet of literature survey on liquid desiccant assisted dehumidification and cooling

\begin{tabular}{|l|l|l|l|}
\hline Author & \multicolumn{2}{|l|}{ System } & $\begin{array}{l}\text { Performance } \\
\text { (COP) }\end{array}$ \\
\hline Sethi and Sharma [36] & Description & Desiccant type & $\mathrm{CaCl}_{2}$ \\
\hline Goshayshi et al. [37] & Analytical & 0.34 \\
\hline Maheshwari et al. [38] & Experimental & $\mathrm{CaCl}_{2}$ & 0.21 \\
\hline Heidarinejad et al. [39] & Simulation & $\mathrm{Li}-\mathrm{Br}$ & $0.74-1.19$ \\
\hline Wu et al. [40] & Experimental & $\mathrm{LiCl}$ & $0.2-1.3$ \\
\hline Dessouky [41] & Simulation & $\mathrm{Li}-\mathrm{Br}$ & 1.67 \\
\hline Stoitchkov and Dimitrov [42] & Experimental & Water & 0.58 \\
\hline
\end{tabular}

\subsection{Effect of Key Variables on The Performance of the Liquid Desiccant Cooling System}

Flooding rates in packed-bed conditioners must be high, both to ensure complete wetting of the packing and to prevent heating of the desiccant. Although the first objective-complete wettingmight be realized at low flow rates by adding surfactants to the desiccant or treating the surface of the packing to increase its surface energy, the second - keep the desiccant cool—will always require a high flooding rate. Figure 4 [43] shows the temperature rise that occurs when a $43.2 \%$ solution of lithium chloride initially at $29.42^{\circ} \mathrm{C}$ adiabatically absorbs water vapor. If the quantity of absorbed water decreases the desiccant's concentration to $42 \%$ and the desiccant is not cooled, the temperature of the desiccant will increase to $54.45^{\circ} \mathrm{C}$. Whereas, initially the desiccant has an equilibrium dew point of $11.21^{\circ} \mathrm{C}$, the $42.12 \%$ solution at the higher temperature has an equilibrium dew point of $36.12^{\circ} \mathrm{C}$ - a value much too high to be useful. If the more dilute desiccant is cooled to $29.47^{\circ} \mathrm{C}$, its equilibrium dew point would be $12.17^{\circ} \mathrm{C}$, and the desiccant could continue to dehumidify air.

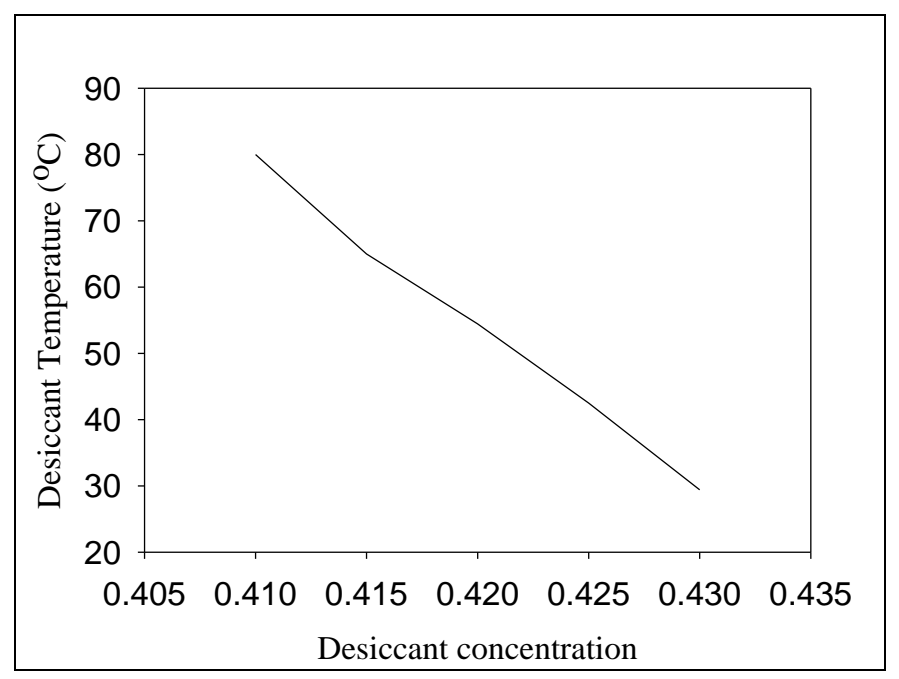

Figure4. Influence of desiccant concentration on temperature rise during adiabatic desorption process.

The improvement in COP produced by higher temperatures in scavenging-air regenerators results from the exponential dependence of the desiccant's equilibrium water vapor pressure as shown in Figure 5. The hot desiccant that flows down the contact surfaces loses energy through both heat and 
mass exchange with the air. The convective heat exchange is a parasitic loss that cools the desiccant without increasing its concentration. Since the driving potential for mass exchange - the desiccant's equilibrium vapor pressure - increases exponentially with its temperature, but the driving potential for heat exchange increases linearly, a greater fraction of the input thermal energy will produce useful mass exchange when the regenerator operates at higher temperatures. The COP of a scavenging-air regenerator can be increased by preheating the air through heat exchange with the hot exhaust. In laboratory tests, Slayzak [44] reported that an internally heated regenerator operating at $93.34^{\circ} \mathrm{C}$ and processing $40 \%$ lithium chloride has a COP of 0.723 without heat recovery and 0.832 with heat recovery by a $70.2 \%$ effective heat exchanger.

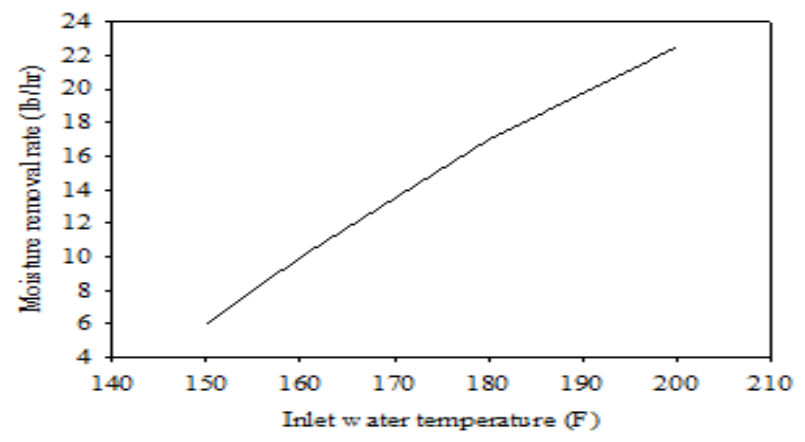

(a)

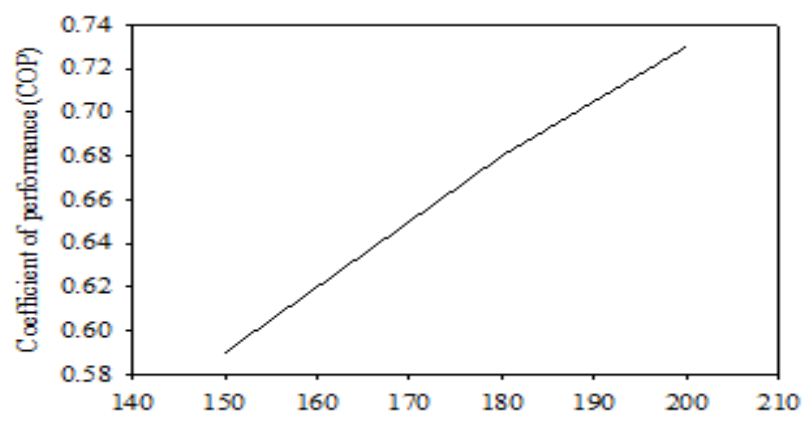

(b)

Figure5. Influence of rise in regenerator water temperature at inlet on (a) moisture removal rate and $(b)$ coefficient of performance of the liquid desiccant cooling system.

A packing material is a medium for liquid desiccant to interact with the process air stream to extract water vapor. A packing material must be inert to liquid desiccants. Packing materials and their configuration significantly affect the performance of dehumidification unit of the desiccant cooling system. They are broadly classified as regular/ structured packing and random packing based on their configuration. Regular packing ameliorates the performance of the dehumidifier by providing lowpressure drop for the air stream and is easy to install as compared with random packing. It also lowers the liquid desiccant resistance in the dehumidification unit. On the other hand, random packing material cannot adjust to the variation in liquid desiccant flows and results in uneven distribution of the desiccant solution over the surface of the packing material, which diminishes the performance of the dehumidification system. However, regular packing is costlier than random packing Some common examples of random packing material include ceramic, plastic, polypropylene pall whereas structured packing material are either gauze type or sheet type. Structured packing materials are generally made of stainless steel-corrugated orifice plate, celdek, etc. Table 2 shows a summary of observations from different investigators.

Table2. Influence of different types of packing materials used in absorber on system performance

\begin{tabular}{|c|c|c|}
\hline Author & Type of packing material & Effect \\
\cline { 1 - 1 } Das and Jain [45] & & Lowers carry over \\
\hline Ahmed et al. [46] & PVDF membrane & High dehumidification capacity \\
\hline Bassuoni [47] & Silica gel & Higher effectiveness \\
\hline Kumar and Asati [48] & Structured packing & Uneven distribution of desiccant \\
\hline
\end{tabular}




\subsection{Comparison of Liquid Desiccant with Traditional Vapor Compression Cooling}

Water vapor content or moisture of conditioned air can be controlled either by condensing the water vapour or by using suitable absorbents as used in liquid desiccant cooling systems. While conventional air conditioners simultaneously cool and dehumidify the air, a desiccant system first only dehumidifies it and later cools the same. Moreover, a desiccant system can be used in combination with evaporative cooling system to maintain the temperature and moisture of conditioned room air. Previously, the desiccant cooling systems were used for industrial and agricultural sector like textile mills, post-harvest crop storage units for humidity control and drying [49]. However, energy crisis and necessity to develop more eco-friendly systems have led to the introduction of desiccant cooling systems as an effective method to control humidity. Table 3 [50-51] provides a brief summary of major differences between the liquid desiccant systems and vapor compression based conventional air conditioners.

Table3. Comparison between traditional coolers and liquid desiccant assisted innovative cooling

\begin{tabular}{|c|c|c|}
\hline Parameter & Conventional air & Liquid desiccant cooling \\
\hline Onerating cost & $\begin{array}{c}\text { conditioner } \\
\text { High }\end{array}$ & Saves $41-48 \%$ \\
\hline Indoor air quality & Average & High \\
\hline Effect on environment & Harmful & Eco-friendly \\
\hline Energy source & Electricity & $\begin{array}{l}\text { Low grade heat like waste heat or } \\
\text { renewable solar energy }\end{array}$ \\
\hline Moisture removal capacity & Average & High \\
\hline
\end{tabular}

\subsection{Future Scope in Various Applications of Liquid Desiccant Assisted Dehumidification and Cooling}

Liquid-desiccant dehumidification advanced cooling technology has made great strides in the past few decades, and some are commercialized and successfully used in many applications to satisfy industrial dehumidification and residential thermal cooling needs of the society. Theoretical models about desiccant dehumidification have been established and insightful analysis has been performed [52-55]. However, it is still uncertain about the exact process of mass and heat transfer, such as the absorption heat distribution between desiccant solution film and process air, wetting ratio of the desiccant solution over the packing sheets in dehumidifier, etc. Although liquid-desiccant dehumidification systems can easily realize the separate handing of temperature and humidity of the moist air to be cooled and processed, but it has the potential limitation about is utility in mild ambient, which hinder its widespread applications, besides, its continuous operation and performance is greatly affected by the changeable environmental conditions at various geographical locations on earth, since the performance of solar collector is mainly judged partly by the ambient air conditions and solar radiations received. Therefore, the system performance is deviated much according to the existing ambient conditions as compared with that of vapor compression based conventional air conditioning units. The emergence of hybrid systems will partly reduces the system's instability, besides, hybrid system's capacity for handling the sensible cooling of the process air far outweigh that of conventional sensible type coolers, which is commonly employed by the traditional liquid-desiccant dehumidification and cooling systems in various industrial and residential applications. Furthermore, the evaporation cooler's cooling efficiency is limited by the geometrical environmental existing situations [56-60]. Above all, hybrid systems should be lied emphasis on to wide spread popularity of desiccant dehumidification assisted cooling techniques for space comfort monitoring. Also, further analytical and experimental research and innovations should be made to still further depth so that the understanding of mass and heat transfer occurring within the dehumidifier can ameliorate further the system's overall performance for its better suitability.

\section{CONCLuSion}

One of the important aspects over the use of liquid desiccant dehumidification and cooling system in building air conditioning is that it can efficiently eliminate the major content of the latent part that consists of mainly the moisture heat of the processed air and regenerate it with low temperature using freely available energy such as solar and waste energy. This review has revealed that liquid-desiccant assisted dehumidification and cooling technique is an economic and environmental friendly cooling 
technology that can be improved further by coupling it judiciously with the other traditional air conditioning techniques. There are many innovations and improvement that can demand several design optimizations in liquid desiccant assisted cooling systems like as carry-over of liquid desiccant at high flow rates, reverse dehumidification at low air humidity ratios and corrosion of the dehumidification unit and storage tank in case of any leakages. Many investigators have suggested that the problem of carry-over can be by using micro-porous membrane, which would only allow the air to pass and not the liquid desiccant. However, such membrane also increases the mass transfer resistance. The present summary about the liquid desiccant cooling show that the liquid desiccant systems have been successful in efficiently eliminating the latent and sensible load to a considerable extent. Thus, replacing conventional vapor compression with hybrid desiccant systems would increase the energy savings potential of this innovative cooling technology considerably in present HVAC market.

\section{REFERENCES}

[1] L.C.S. Mesquite, S.J. Harrison, D. Thomey, Modeling of heat and mass transfer in parallel plate liquid desiccant dehumidifiers, Solar Energy 38 (2006)1475-1482.

[2] V.C. Mei, F.C. Chen, Z. Laven, R.K. Collier, G. Meckler, An Assessment of Desiccant Cooling and Dehumidification Technology, Oak Ridge National Laboratory, Virginia, 1992.

[3] G. Nesreen, G. Kamel, N. Antoine, Use of desiccant dehumidification to improve energy utilization in airconditioning systems in Beirut, International Journal of Energy Research 27 (2003) 1317-1338.

[4] S.M. Nayak, Experimental and Theoretical Investigation of Integrated Engine Generator-Liquid Desiccant System, Faculty of the Graduate School of the University of Maryland, Maryland, 2005 (PhD thesis).

[5] B.S. Davanagers, A. Shrif, D.Y. Goswami, A feasibility study of a solar desiccant air-conditioning system-Part I: psychrometrics and analysis of the conditioned zone, International Journal of Energy Research 23 (1999) 7-12.

[6] G. Scalabrin, G. Scaltriti, A liquid sorption-desorption system for air conditioning with heat at lower temperature, Journal of Solar Energy Engineering 112(1990) 70-75.

[7] W.Z. Gao, J.H. Liu, Y.P. Cheng, X.L. Zhang, Experimental investigation on the heat and mass transfer between air and liquid desiccant in a cross-flow dehumidifier, Renewable Energy 37 (2012) 117-123.

[8] X.H. Liu, Y. Jaing, X.M. Chang, X.Q. Yi, Experimental investigation of the heat and mass transfer between air and liquid desiccant in a cross-flow regenerator, Renewable Energy 32 (2007) 1623-1663.

[9] A.Th. Mohammad, Sohif Bin Mat, M.Y. Sulaiman, K. Sopian, Abduljalil A. Al-abidi, Implementation and validation of an Artificial Neural Network for predicting the performance of a liquid desiccant dehumidifier, Energy Conversion and Management 67 (2013) 240-250.

[10] L. Yutong, Y. Hongxing, Investigation on solar desiccant dehumidification process for energy conservation of central air-conditioning systems, Applied Thermal Engineering 28 (2008) 1118-1126.R. Kumar, Studies on Standalone Liquid Desiccant Based Air Conditioning Systems, Mechanical Engineering Department, IIT, Delhi, 2008.

[11] D. Peng, X. Zhang, Modeling and performance analysis of solar air pretreatment collector/regenerator using liquid desiccant, Renewable Energy 34 (2009)699-705.

[12] Z. Xiong, Y.J. Dai, R. Wang, Development of a novel two-stage liquid desiccant dehumidification system assisted by $\mathrm{CaCl} 2$ solution using exergy analysis method, Applied Energy 87 (2010) 1495-1504.

[13] H.-M. Hellmann, G. Grossman, Simulation and analysis of an open-cycle dehumidifier-evaporatorregenerator (DER) absorption chiller for low-grade heat utilization, International Journal of Refrigeration 18 (1995) 1177-1189.

[14] J.P. Pohl, H.-M. Hellmann, G. Grossman, Investigation and comparison of two configurations of a novel open-cycle absorption chiller, International Journal of Refrigeration 21 (1998) 142-149.

[15] K. Gommed, G. Grossman, F. Ziegler, Experimental investigation of a LiCl-water open absorption system for cooling and dehumidification, Journal of Solar Energy Engineering: Transactions of the ASME 126 (2004) 710-715.

[16] K. Gommed, G. Grossman, A liquid desiccant system for solar cooling and dehumidification, Journal of Solar Energy Engineering: Transactions of the ASME 126(2004) 879-885.

[17] K. Gommed, G. Grossman, Experimental investigation of a liquid desiccant sys-tem for solar cooling and dehumidification, Solar Energy 81 (2007) 131-138.

[18] B.M. Jones, First results of a solar-thermal liquid desiccant air conditioning concept, in: 1st International Congress on Heating, Cooling and Building, Lisbon, Portugal, 2008. 
[19] A.R. Martinez, Solar Cooling and Dehumidification, Cracas, Venzuela, 1980.

[20] R. Yang, W.J. Yan, Simulation study for an open cycle absorption solar cooling system operated in a humid area, Energy 17 (1992) 649-655.

[21] R. Yang, P.L. Wang, A simulation study of performance evaluation of single-glazed and double-glazed collectors/regenerators for an open cycle absorption solar cooling system, Solar Energy 71 (2001) 263268.

[22] R. Yang, P.L. Wang, Experimental study of a forced convection solar collector/regenerator for open cycle absorption cooling, Solar Energy Engineering116 (1994) 194-199.

[23] R. Kumar, P.L. Dhar, S. Jain, A.K. Asati, Multi absorber stand alone liquid desiccant air-conditioning systems for higher performance, Solar Energy 83 (2009)761-772.

[24] S. Jain, P.L. Dhar, S.C. Kaushik, Evaluation of liquid desiccant based evaporative cooling cycles for typical hot and humid climates, Heat Recovery System and CHP 14 (1994) 621-632.

[25] X.-W. Li, X.-S. Zhang, Photovoltaic-electro dialysis regeneration method for liquid desiccant cooling system, Solar Energy 83 (2009) 2195-2204.

[26] N. Audah, N. Ghaddar, K. Ghali, Optimized solar-powered liquid desiccant sys-tem to supply building fresh water and cooling needs, Applied Energy 88 (2011)3726-3736.

[27] S. Jain, S. Tripathi, R.S. Das, Experimental performance of a liquid desiccant dehumidification system under tropical climates, Energy Conversion and Management 52 (2011) 2461-2466.

[28] Ali, K. Vafai, A.-R.A. Khaled, Comparative study between parallel and counter flow configurations between air and falling film desiccant in the presence of nano particle suspensions, International Journal of Energy Research 27 (2003)725-745.

[29] C.S. Ahmed Kalid, P. Gandhidasan, A.A. Al-Farayedhi, Simulation of a hybrid liquid desiccant based airconditioning system, Applied Thermal Engineering17 (1997) 125-134.

[30] G. Grossman, Solar powered system for cooling, dehumidification and air conditioning, Solar Energy 72 (2002) 53-62.

[31] P. Gandhidasan, M.A. Mohandes, Artificial neural network analysis of liquid desiccant dehumidification system, Energy 36 (2011) 1180-1186.

[32] D. Babakhani, M. Soleymani, A. Moheb, Heat and mass transfer between air and liquid desiccant in crossflow contact systems, International Journal of Energy Research 33 (2010) 281-291.

[33] Lowenstein, Review of liquid desiccant technology for HVAC applications, HVAC\&R 14 (2008) 819-839.

[34] A.T. Mohammd, S.B. Mat, M.Y. Sulaiman, K. Sopian, A.A. Al-abidi, Historial review of liquid desiccant evaporation cooling, Enegy and Buildings 67 (2013) 22-23.

[35] V.P. Sethi, S.K. Sharma, Survey of cooling technologies for world-wide agricultural greenhouse applications, Solar Energy 81 (2007)1447-1459.

[36] H.R. Goshayshi, J.F. Missenden, R. Tozer, Cooling tower-an energy conservation resource, Applied Thermal Engineering 19 (1999) 1223-1235.

[37] G.P. Maheshwari, F. Al-Ragom, R.K. Suri, Energy saving potential of an indirect evaporative cooler, Applied Energy 69 (2001) 69-76.

[38] G. Heidarinejad, M. Bozorgmehr, S. Delfani, J. Esmaeelian, Experimental investigation of two-stage indirect/direct evaporative cooling system in various climatic conditions, Building and Environment 44 (2009)2073-2079.

[39] J.M. Wu, X. Huang, H. Zhang, Theoretical analysis on heat and mass transfer in a direct evaporative cooler, Applied Thermal Engineering 29 (2009) 980-984.

[40] H. El-Dessouky, Enhancement of the thermal performance of a wet cooling tower, Canadian Journal of Chemical Engineering 74 (1996) 331-338.

[41] N.J. Stoitchkov, G.I. Dimitrov, Effectiveness of cross flow plate heat exchanger for indirect evaporative cooling, International Journal of Refrigeration 21 (1998) 463-471.

[42] X.Y. Chen, Y. Jiang, Z. Li, and K.Y. Qu, Field study on independent dehumidification air-conditioning system - I: performance of liquid desiccant dehumidification system, ASHRAE Transactions 111(2005) 271-76.

[43] S. Slayzak, J. Ryan, A. Pesaran, and A. Lowenstein, Advanced commercial liquid-desiccant technology development study. NREL/TP-550-24688, Golden, CO, 1998.

[44] R.S. Das, S. Jain, Experimental performance of indirect air-liquid membrane contactors for liquid desiccant cooling systems, Energy 57 (2013) 319-25. 
[45] S.Y. Ahmed, P. Gandhidasan, A.A. Al-Farayedhi, Thermodynamic analysis of liquid desiccants, Solar Energy 62 (1998) 11-8.

[46] M.M. Bassuoni, An experimental study of structured packing dehumidifier - regenerator operating with liquid desiccant, Energy 36 (2011) 2628-38.

[47] R. Kumar, A.K. Asati, Simplified mathematical modeling of dehumidifier and regenerator of liquid desiccant system, Int J Curr Eng Technol 4 (2014) 557-63.

[48] D.B. Jani, M. Mishra, P.K. Sahoo. Solid desiccant air conditioning - A state of the art review. Renewable and Sustainable Energy Reviews 2016; 60:1451-1469.

[49] D.B. Jani, M. Mishra, P.K. Sahoo. Performance studies of hybrid solid desiccant-vapor compression airconditioning system for hot and humid climates. Energy and Buildings 2015; 102:284-292.

[50] K.K. Bhabhor, D.B. Jani. Progressive development in solid desiccant cooling : A review. International Journal of Ambient Energy 2019;DOI:10.1080/01430750.2019.1681293.

[51] D.B. Jani, K.K. Bhabhor, M. Dadi et al. A review on use of TRNSYS as simulation tool in performance prediction of desiccant cooling cycle. Journal of Thermal Analysis and Calorimetry 2019; DOI: 10.1007/s10973-019-08968.

[52] M. Sahlot, S.B. Riffat, Desiccant cooling systems: a review, International Journal of Low-Carbon Technologies 11 (2016) 489-505.

[53] D.B. Jani. An overview on recent development in desiccant materials. International Journal of Advanced Materials Research 2019; 5(2):31-37.

[54] L. Mei, Y.J. Dai, A technical review on use of liquid-desiccant dehumidification for air-conditioning application, Renew Sustain Energy Rev 12 (2008) 662-89.

[55] D.B. Jani. Progressive review on use of desiccant drying in agricultural applications. Journal of Agricultural Science and Engineering 2019; 5(1):24-31.

[56] X.W. Li, X.S. Zhang, R.Q. Cao, Progress in selecting desiccant and dehumidifier for liquid desiccant cooling system, Energy Build 49 (2012) 410-8.

[57] Joshi, D.B. Jani. A review on desiccant based cooling and dehumidification systems. International Journal of Innovative Knowledge Concepts 2018;6(2):218-221.

[58] D.B. Jani. Application of Renewable solar energy in liquid desiccant powered dehumidification and cooling. Journal of Environmental Protection and Sustainable Development 2019;5:1-6.

[59] D.B. Jani, Liquid desiccants application in cooling and dehumidification - An overview, Archives of Industrial Engineering 2 (2019) 1-17.

Citation: D.B. Jani (2020) "Application of Liquid Desiccant Cooling Technology in Built Environment: A Review”, International Journal of Modern Studies in Mechanical Engineering, 6(1), pp. 9-18. DOI: http://dx.doi. org/10.20431/2454-9711.0601002.

Copyright: () 2020 Authors, This is an open-access article distributed under the terms of the Creative Commons Attribution License, which permits unrestricted use, distribution, and reproduction in any medium, provided the original author and source are credited. 